\title{
Human Resource Management: A Review with Applications to Agriculture
}

\author{
Wayne H. Howard ${ }^{1}$ and Kenneth A. McEwan ${ }^{2}$ \\ ${ }^{1}$ Assistant professor, Department of Agricultural Economics and Business, \\ University of Guelph, Guelph. \\ ${ }^{2}$ Farm management specialist, Ontario Ministry of Agriculture and Food, \\ Toronto.
}

\section{INTRODUCTION}

For years the major management concern of farm managers was farm production. In the 1970s and 1980s, the importance of finance and marketing emerged as two additional critical success factors in production agriculture. A fourth management area of growing importance to successful farming is managing labor (Thomas and Erven 1989). Total employment in farming has been steadily decreasing to less than 4\% of Canada's labor force in 1984 from close to $20 \%$ in 1950 (Agriculture Canada 1984). However, the labor remaining in agriculture has been changing structure, with a greater proportion of hired labor. Hired labor accounted for $30 \%$ of total hours of Canadian agricultural labor in 1983, up from $18 \%$ in 1961 (Statistics Canada 1981, 1971). A similar situation exists in U.S. agriculture.

The increasing proportion of hired labor in agriculture indicates a need for more research and extension activities in labor issues, but the importance of personnel management is not universally recognized in our discipline. Most studies of agricultural labor have been on agricultural versus nonagricultural wage rates (Tweeten and Brinkman 1976), supply of seasonal labor (Torok and Huffman 1986), or labor productivity in the aggregate (Polopolus 1986). A recent survey of introductory farm management course syllabi and commonly used farm management textbooks found that, whereas $70 \%$ of the texts had a chapter on labor, only $35 \%$ of the syllabi listed labor as a subject explicitly discussed (Howard and Harling 1988).

The purpose of this paper is to present some common human resource management (HRM) theories. The theories presented are not exhaustive, but they present a useful framework for analyzing HRM practices. A brief review of HRM studies in agriculture is also presented. A summary and recommendations for future research conclude the paper.

\section{HUMAN RESOURCE MANAGEMENT}

Neoclassical economic theory assumes that labor, as one of the three factors of production, is homogeneous, perfectly mobile, perfectly informed, and can adjust 
instantaneously to a new equilibrium quantity, given a change in relative prices. These assumptions, however, are not supported by empirical work. Labor is heterogeneous in ability, not always ready and willing to move, and may not be aware of opportunity costs. Recent studies also indicate that labor is better modeled as a quasi-fixed input rather than as a variable (e.g., Howard and Shumway 1988).

Human resource management theories recognize that employees are heterogeneous in their abilities, often geographically limited and unaware of their options, and that hiring and firing employees incurs positive adjustment costs. Microeconomics and HRM do agree that individuals are motivated by utility functions but, where microeconomics is axiomatic and predictive, HRM is situational and explanatory.

Microeconomics and HRM are not mutually exclusive; in fact, when microeconomics becomes ambiguous in dealing utility functions, HRM theories can be used to explain and analyze the situation. An example could be the decision of how much labor to hire. Assume a farmer who behaves as if she/he is maximizing utility, which is a function of profit, $\pi$, and leisure, $l$, such that:

$$
\begin{gathered}
U(\pi, l) \\
\pi=P H(X, F, L)-W^{\prime} X-C^{\prime} L
\end{gathered}
$$

and

$$
l=24-F+L
$$

where

$$
\begin{aligned}
H() & =\text { a well-behaved production function, } \\
X & =\text { all other inputs, } \\
F & =\text { owner/operator and/or family labor, } \\
L & =\text { hired labor, and }
\end{aligned}
$$

$P, W$, and $C=$ vectors of output, input, and hired labor prices.

The producer has a trade-off between hiring more labor to increase the family's leisure time, and minimizing hired labor in order to maximize profits. Substituting Eqs. 2 and 3 into Eq. 1 and differentiating with respect to hired labor gives:

$$
U_{\pi}\left[P H_{L}-C\right]=-U_{l}
$$

Rearranging and letting $M V P_{L}=P H_{L}$ yields:

$$
M V P_{L}=C-U_{\mu} U_{\pi}
$$

From Eq. 5 one can see that as marginal utility of leisure increases, the real cost of hired labor to the producer decreases; hence more labor is employed. The greater the farmer's marginal utility of profit, the closer hired labor approaches the economically optimal amount employed. A similar exercise can be done for the marginal value of family labor:

$$
M V P_{F}=U_{l} / U_{\pi}
$$


The greater the marginal utility of leisure (profit), the lower (greater) the amount of family labor employed.

A producer's decision to employee hired labor is a function of the producer's utility function, while a similar argument can be made for labor's decision to work in a particular position. This is not a new idea, but one that has not been explored in farm management. The HRM theories provide a framework from which to approximate and evaluate possible utilities for both employers and employees.

\section{HRM AS A PROCESS}

As a process, HRM is a comprehensive term that includes attracting and hiring good people, developing them to their potential, and directing the course of their careers (Gram 1986). For a farmer who has made the decision to hire an employee, HRM is the process of attracting, keeping and motivating employees. There are many factors affecting the attracting, keeping and motivating of labor, and they are not easily separated; a factor that attracts an employee to a position is very likely to keep them in that position.

\section{THE HRM TERRITORY MAP}

A framework that explicitly recognizes the interaction of the various factors can facilitate the analysis of the processes of attracting, keeping and motivating. The HRM teritory map in Figure 1, adapted from Beer et al (1985), is such a framework. At the center of the map are four HRM policy areas: reward systems, work systems, human resource flow, and employee influence. Reward systems refer to compensation in all forms: wages, benefits, bonus, incentives, and perquisites. Work systems are the technical relationships between labor, capital and other resources. Employees are recruited, selected, hired, trained and terminated in the human resource flow. Employee influence is the amount of input employees have into the work systems. The influence can range from none to a suggestion box, to having a labor representative on the board of directors.

The outcomes of the HRM policies are shown by the commitment of employees to the organization, their competence, the congruence of labor and management's goals, and the cost effectiveness of the organization.

The long-run consequences of HRM policies are the organization's effectiveness in meeting its goals. The degree of effectiveness will in part determine the organization's members' well-being and, for all organizations, society's wellbeing. These long-run consequences will effect the goals and objectives of the stakeholder' interests, i.e., what owners, employees, and other parties with an interest in an organization's HRM policies want from those policies. The longrun consequences will also affect the situational factors that influence HRM policies.

The HRM territory map is a framework that suggests rather than a model that clearly defines relationships. An analogy is that demand is a function of relative 


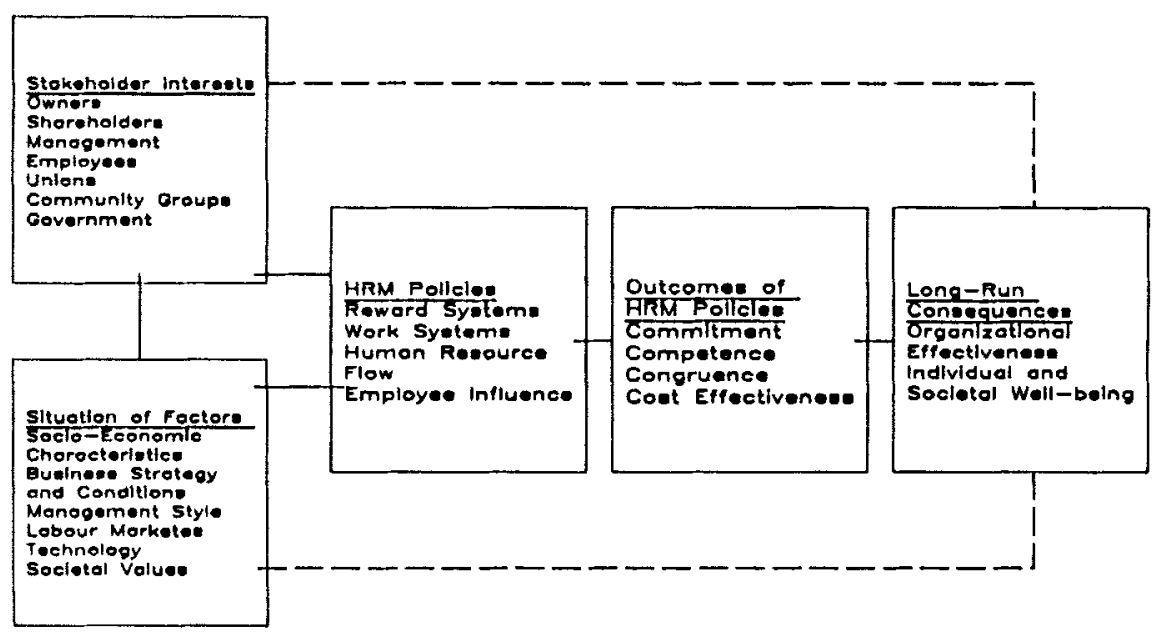

Figure 1. Human resource management territory map

prices and other factors. An employee's commitment is a function of compensation and other factors. The territory map suggests what those other factors could be. Further, an organization that takes into account the stakeholder's interests and situational factors will likely have optimal HRM polices. Those policies will pay off in employee commitment, competence, and cost effectiveness.

\section{HRM POLICIES}

The HRM territory map provides a framework to analyze the observable HRM processes. The processes of recruitment, reward systems, employee turnover, job satisfaction, motivation and management style can be discussed within that framework.

\section{Recruitment}

Effective recruitment identifies qualified applicants, influences their willingness to accept employment, and can even create a positive image of the employer among those not hired. In periods of scarce labor, employers give greater emphasis to attracting than to screening applicants (Rynes and Milkovich 1986). There are no data on demand for skilled agricultural labor, but, as White $(1988,82)$ puts it, "Anecdotal evidence is overwhelming that ... labor availability is a prime constraint to agricultural productivity." Further, many farmers attending a recent seminar on labor management in New York stated difficulty in " ... finding and keeping good help" (Maloney 1988). Common methods used to notify potential employees about a vacant position include visiting college and other school placement centers, advertisements in newspaper and trade journals, employment centers, and asking current employees for suggestions. 
Job requirements and duties should be carefully analyzed, which will aid in determining the skills required. If specifications are too high, few applicants will be generated. If specifications are too low, however, large numbers of diverse applicants may be attracted, which will increase screening costs and time.

\section{Reward Systems}

In tight labor markets, firms must offer more inducements than they would otherwise in order to attract and keep employees (Beer et al. 1985). The importance an employee places on the reward system and the components within the system can vary with both external and internal factors. Money income will be more important in periods of high inflation, while slow growth or high unemployment will make job security more important. Wages are also viewed differently in early, middle and later careers. Other rewards, such as status, growth and security, also change over a person's lifetime.

A reward system should be congruent with overall management philosophy. If wages and other extrinsic rewards (e.g., incentive plans, bonuses) are tied to performance, then management is signaling that management, not the individual, is in control. Beer et al point out that tight management control can reduce the employee's feeling of competence and self-determination. Intrinsic motivation is thus reduced, and an employee's overall motivation and performance may be reduced.

External rewards in the form of incentive plans may even promote dysfunctional behavior. A plan to lower feed costs at a hog operation can result in underweight hogs. However, in many situations, especially where the work is repetitive and boring, extrinsic rewards can be advantageous. Piecework has a long history in agriculture, particularly in harvesting.

The HRM literature has no consensus on reward systems. Incentive and other pay-for-performance plans have strong advantages, but only if well planned. Rewards based on other than performance risks pay for poor performance. The advantages of defining what constitutes good performance and encouraging that behavior is a worthwhile goal for any organization and should not be taken lightly. The problems occur in the implementation.

\section{Employee Turnover}

Employee turnover is thought to be a disruptive, costly process, which most employers want to minimize. Rapid employee turnover increases costs as a result of increased retruitment, decreased production efficiency, disruption or the organization's social and communication network, and a general decline in morale. Additionally, management may respond to increased turnover with inappropriate and at times counterproductive responses. However, an optimum amount of turnover can benefit an organization. Culling poor performers can increase an orga- 


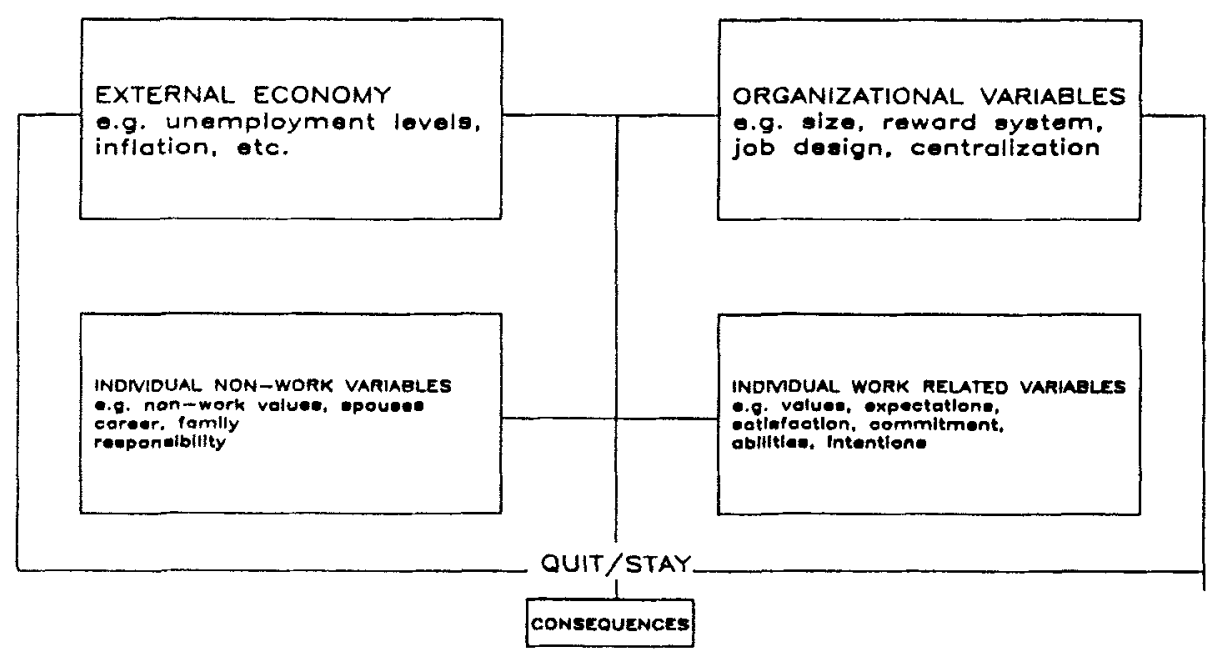

Figure 2. A simplified model of the causes and correlates of turnover

nization's efficiency and morale and in some case reduce apathy and even workrelated conflict.

Four general classes of factors that determine turnover are displayed schematically in Figure 2 (adapted from Mobley 1982). Two of these classes are beyond the control of the employer: the general state of the economy and the values and family situation of employees should be treated as given. Factors that employers can affect are their organizational variables and some of the individual work-related variables. These employer-controlled wariables affect what can be generally called "job satisfaction."

\section{Job Satisfaction}

Locke (1987) defines job satisfaction as “ ". . . a pleasurable or positive emotional state resulting from the appraisal of one's job or job experience," or the emotional response to job situations. As with any attitude, satisfaction can not be observed but must be inferred from either behavior or statements. Herzberg (1968) proposes that satisfaction is a function of achievement, recognition (cash and noncash rewards), the work itself and growth. The satisfaction an employee feels about a job is balanced against dissatisfaction caused by regulations, supervision, work conditions and (lack of) rewards.

The balance between the two forces is delicate but very important, as satisfaction is a key factor determining an employee's performance. Vroom (1964) finds significant correlations between satisfaction and turnover, absenteeism, and even better mental and physical health. Employees with higher levels of job satisfaction even have fewer on-the-job accidents. 


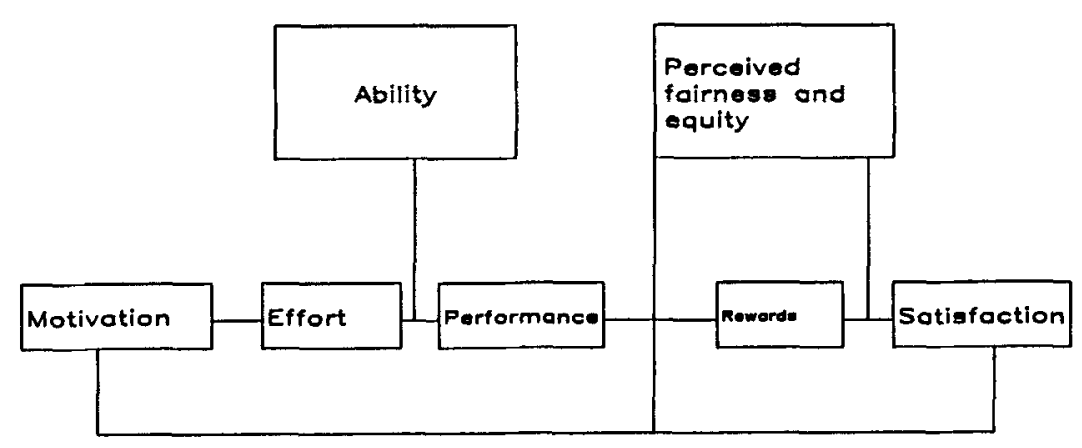

Figure 3 . The expectancy theory and model

\section{Motivation}

The concepts of motivation and performance are not synonymous. Motivation represents an employee's desire to perform, while performance is the extent to which an individual can successfully accomplish a task or achieve a goal. Performance is also affected by ability and opportunity.

The relationship between motivation and performance can be explained by the expectancy model depicted in Figure 3. In this model, motivation to exert effort is triggered by the proposed rewards. When effort leads to performance and performance to desired rewards, the employee is satisfied and motivated to perform again. Ability also affects performance, as does the training and information provided by the organization.

More than 50 studies have validated the expectancy approach to predicting employee behavior (Nadler and Lawler 1983). The best performers in an organization tend to see a strong relationship between performing their jobs well and receiving the rewards they value. Additionally, those employees have clear performance goals and feel they are unencumbered to perform their jobs well. Similar studies using expectancy theory to predict how people choose their jobs show that individuals tend to interview for and take those jobs they feel will provide the rewards they value.

Given the above, for an employer to optimize employee performance, the employer should:

- determine what rewards each employee values;

- determine desired behavior in terms of quantity and quality of work;

- ensure the rewards are attainable;

- ensure the rewards have clear linkage to performance and are large enough to affect behavior;

- watch for conflicting expectations; and

- strive for fairness and equity in reward determination. 


\section{EMPIRICAL WORK IN ON-FARM HRM}

There have been few studies published on HRM in agricultural, but labor has been recognized as a problem in agriculture for many years. Lane and Campbell (1952) found acquiring and keeping adequate farm labor to be one of the most common and difficult problems confronting Ontario farmers. They identified regular hours, good living conditions and good wages as the factors most important in keeping labor.

McBride surveyed employees on dairy farms in 1969. Those employees ranked good wages, good housing and regular hours worked as the top priorities when applying for new positions. Dairy employees were surveyed again by Okyere (1972), who found that employee satisfaction was highly correlated with the image the employee holds of the dairy industry as a whole. Okyere also found a negative relationship between education and employee turnover.

Many studies have pointed out that wages in agriculture are lower than wages in nonagricultural industries. Newby (1972) attempted to answer why at least some employees are satisfied with lower wages. From British farm employees, he gathered information on job satisfaction, goals and expectations, as well as normal wages and employment statistics from the British Ministry of Labour. Essentially he concluded there were three reasons for lower agricultural wages:

- In general, the productivity of labor in agriculture is well below that in industry or services.

- Compared with most manual work, agriculture offers greater noneconomic rewards. However, the tolerance of lower income for the sake of noneconomic rewards is extremely sensitive.

- The aspirations and expectations of individuals are shaped by the norms and values of other individuals and groups with whom they identify.

Also in Britain, Gasson (1974) investigated the relationship between the size of a farm labor force and turnover, concluding that there is a negative relationship between them. Hence, there is no evidence that employees on smaller farms derive more satisfaction from their work and working environment.

Lastly, Jensen (1982) focused on farm labor fringe benefits. He concluded the structure of labor plays a large part in determining benefits received; since unionized workers typically receive more employer-paid benefits, so nonunionized agriculture (and construction to a degree) has historically paid fewer benefits than manufacturing. However, Jensen found no strong correlation between the size of the firm and the level of fringe benefits received.

\section{SUMMARY AND RECOMMENDATIONS}

Human resource management is concerned with attracting, keeping and motivating labor. Some factors affect processes that are beyond the control of employers, such as the general level of the economy and societal and individual values. However, 
employers do control reward systems, which directly affect employees' job satisfaction, motivation and turnover.

The HRM literature is extensive, but few studies have been looked into the effects of HRM policies on farms. To help farmers develop optimal HRM policies, researchers need to examine:

- any problems in attracting, keeping ånd motivating employees on farms, and the magnitudes of those problems;

- the current reward systems in terms of salary, benefits, perquisites and bonuses, relative to nonagricultural compensation;

- the socio-economic characteristics of labor currently employed on farms, i.e., age, education, work experience, marital status, career plans, personality traits and job attitudes; and

- the types and extent of relationships between job satisfaction, management style and HRM policies, and labor performance.

\section{REFERENCES}

Agriculture Canada. 1984. Selected agricultural statistics, Canada and the provinces. Ottawa: Agriculture Canada, Regional Development Branch.

Beer, Michael, Bert Spector, Paul R. Lawrence, D. Quinn Mills and Richard E. Walton. 1985. Human Resource Management. New York: Free Press.

Gasson, R. 1974. Turnover and size of labor force on farms. Journal of Agricultural Economics 25: 115-27.

Gram, H. 1986. An Introduction to Management. Hall, Rinehart, and Winston.

Herzberg, F. 1968. One more time: How do you motivate employees? Harvard Business Review 1968 (January-February).

Howard, W. H. and K. F. Harling. 1988. Farm management instruction in North America. Guelph: University of Guelph.

Howard, W. H. and C. R. Shumway. 1988. Dynamic adjustment in the U.S. dairy industry. American Journal of Agricultural Economics 70: 837-47.

Jensen, H. 1982. Analysis of fringe benefits for non-metropolitan versus metropolitan employee compensation. American Journal of Agricultural Economics 64: 124-128.

Lane, S. and D. Cambell. 1952. Farm labour in Ontario. Guelph: University of Guelph, Department of Agricultural Economics.

Locke, E. 1987. The nature and causes of job satisfaction. European Economic Review. 31: 1267-83.

Maloney, Thomas R. 1988. Farm labor is in short supply. Agricultural News Service, Cornell Cooperative Extension, April.

Mobeley, W. 1982. Employee Turnover: Causes, Consequences, and Control. Reading, Mass.: Addison-Wesley.

Nadler, David A. and Edward E. Lawler. 1983. Motivation: A diagnostic approach. In Perspectives on Behavior in Organizations, edited by J. Richard Hackman, Edward E. Lawler III, and Lyman W. Porter, pp. 67-78. New York: McGraw-Hill.

Newby, H. 1972. The low earnings of agricultural workers: A sociological appraisal. Journal of Agricultural Economics 23: 15-24. 
Okere, w. 1972. A study of personnel management practices and problems on Ontario dairy farms. MSc thesis. Guelph: University of Guelph.

Polopolus, L. 1986. Labor productivity and agribusiness. Agribusiness 2(3): 269-77.

Rynes, S. L. and G. T. Milkovich. 1986. Current Issues iin Human Resources Management: Commentary and Readings. Business Publications, Inc., Texas.

Statistics Canada. 1981. 1971. Census of Agriculture. Ottawa: Statistics Canada.

Thomas, Kenneth H. and Bernard L. Erven. 1989. Farm personnel management. North Central Regional Extension Publication 329-1989. Ames: Iowa State University.

Torok, S. J. and W. E. Huffman. 1986. U.S.-Mexcian trade in winter vegetables and illegal immigration. American Journal of Agriculture Economics 68: 246-60.

Tweeten, L. and G. Brinkman. 1976. Micropolitan Development: Theory and Practice of Greater-Rural Economic Development. Ames: Iowa State University Press.

Vroom, V. H. 1964. Work and Motivation. New York: John Wiley and Sons.

White, Gerald B. 1988. Changing conditions and emerging issues for agricultural production in the Northeast. Northeastern Journal of Agriculture and Resource Economics 17: 73-84. 